\title{
Viral hepatitis is associated with intrahepatic cholangiocarcinoma with cholangiolar differentiation and $\mathrm{N}$-cadherin expression
}

\author{
Tsan-Hua Yu ${ }^{1,2}$, Ray-Hwang Yuan ${ }^{3}$, Yu-Ling Chen ${ }^{1,2}$, Wan-Ching Yang ${ }^{1,2}$, Hey-Chi Hsu ${ }^{1,2}$ \\ and Yung-Ming Jeng ${ }^{1,2}$ \\ ${ }^{1}$ Graduate Institute of Pathology, National Taiwan University, Taipei, Taiwan; ${ }^{2}$ Department of Pathology, \\ National Taiwan University Hospital, Taipei, Taiwan and ${ }^{3}$ Department of Surgery, National Taiwan \\ University Hospital, Taipei, Taiwan
}

\begin{abstract}
Viral hepatitis-associated intrahepatic cholangiocarcinoma is thought to have common disease processes with hepatocellular carcinoma, but until now the histomorphological and genetic features of viral hepatitisassociated intrahepatic cholangiocarcinoma is still unknown. From 2000 to 2010, 170 patients with intrahepatic cholangiocarcinoma who received detailed pathological assessment and regular follow-up at the National Taiwan University Hospital were selected for this study. Of 170 patients, 69 (41\%) were positive for hepatitis B and/or $\mathrm{C}$ virus. These patients were younger, were more frequently male, and had elevated serum $\alpha$-fetoprotein levels as compared with seronegative intrahepatic cholangiocarcinoma patients. Grossly these tumors were mostly of the mass-forming type, and histologically, cholangiolar differentiation was more frequently seen. We identified $\mathrm{N}$-cadherin as an immunohistochemical marker strongly associated with hepatitis virus infection. The prevalence of viral hepatitis in patients with $\mathrm{N}$-cadherin-positive intrahepatic cholangiocarcinoma was $75 \%$, and that in $\mathrm{N}$-cadherin-negative patients was only $37 \%$. N-cadherin-positive patients were younger, had elevated $\alpha$-fetoprotein, and had no hepatolithiasis. All N-cadherin-positive intrahepatic cholangiocarcinomas were of the mass-forming type. $\mathrm{N}$-cadherin positivity was strongly associated with cholangiolar morphology and lack of carcinoembryonic antigen and MUC2 expression, whereas $K-R A S$ mutations were less frequent. Our results indicate that a subgroup of intrahepatic cholangiocarcinoma characterized by cholangiolar differentiation and $\mathrm{N}$-cadherin expression is strongly associated with viral hepatitis.
\end{abstract}

Modern Pathology (2011) 24, 810-819; doi:10.1038/modpathol.2011.41; published online 18 March 2011

Keywords: cholangiocarcinoma; cholangiole; N-cadherin; viral hepatitis

Intrahepatic cholangiocarcinoma is the second most common primary liver cancer after hepatocellular carcinoma. The incidence of intrahepatic cholangiocarcinoma varies widely around the world. It is more prevalent in East Asia than in western countries. ${ }^{1}$ The high incidence of intrahepatic cholangiocarcinoma in East Asia can most likely be attributed to infections, especially infections

Correspondence: Dr R-H Yuan, MD, PhD, Department of Surgery, National Taiwan University Hospital, 7 Chung-Shan South Road, Taipei, Taiwan or Dr Y-M Jeng, MD, PhD, Department of Pathology, National Taiwan, University Hospital, 7 Chung-Shan South Road, Taipei, Taiwan.

E-mail: d83409009@ntu.edu.tw or mrna0912@yahoo.com.tw

Received 24 September 2010; revised 6 December 2010; accepted 6 December 2010; published online 18 March 2011 with the liver flukes Clonorchis sinesis (C. sinesis) and Opisthorchis viverrini $\left(O\right.$. viverrini). ${ }^{2,3}$ Other known etiological factors for intrahepatic cholangiocarcinoma include hepatolithiasis, primary sclerosing cholangitis, exposure to the radiopaque medium thorium dioxide (Thorotrast), anatomical anomalies of the biliary tract, and hepatitis B and C infection. ${ }^{4-9}$ However, most patients diagnosed with cholangiocarcinoma do not have a recognized risk factor. Complete surgical resection is the only curative treatment for intrahepatic cholangiocarcinoma, but the prognosis remains dismal because the disease is usually advanced at the time of diagnosis. ${ }^{10}$

On the basis of gross morphological features, intrahepatic cholangiocarcinoma can be classified into three subtypes: mass forming, periductal 
infiltrating, and intraductal. ${ }^{11}$ The first is the most common type, in which a definite mass forms within liver parenchyma. The periductal infiltrating type is composed of tumor cells growing longitudinally along large bile ducts. The intraductal type is characterized by tumor cells growing toward the lumina of large bile ducts in a papillary configuration. ${ }^{11}$ The different growth patterns suggest that intrahepatic cholangiocarcinomas are heterogeneous tumors having different cells of origin and different pathogeneses. It is likely that periductal and intraductal tumors arise from malignant transformation of epithelial cells lining the larger bile ducts, whereas the massforming type arises from smaller bile ducts or bipotential hepatic stem cells within portal areas. Therefore, etiologies involving distinct molecular pathways may be associated with the subtypes of intrahepatic cholangiocarcinoma. For example, intrahepatic cholangiocarcinomas associated with hepatolithiasis and $C$. sinesis infection are nearly always found to have the intraductal growth pattern. ${ }^{12,13}$

Hepatitis $\mathrm{B}$ and $\mathrm{C}$ virus infections are the most common risk factors for hepatocellular carcinoma. Rarely, hepatitis-associated hepatocellular carcinoma contains elements of cholangiocarcinoma, ${ }^{14} \mathrm{a}$ finding that suggests a common origin from bipotential stem cells and shared pathogenic mechanisms for the two malignancies. ${ }^{15}$ In addition, several studies from Japan, Korea, China, and Taiwan indicate that viral hepatitis B and C are statistically related to intrahepatic cholangiocarcinoma. ${ }^{8,9,16-18}$ Compared with seronegative intrahepatic cholangiocarcinoma patients, hepatitis B-related intrahepatic cholangiocarcinoma patients tend to be younger and are more frequently male, have higher abnormal aminotransferase and $\alpha$-fetoprotein levels, and lower abnormal serum carbohydrate antigen 19-9 (CA19-9) levels. ${ }^{17}$ Taken together, these findings suggest that hepatitis virus-associated intrahepatic cholangiocarcinoma and hepatocellular carcinoma share common disease processes for carcinogenesis. However, whether hepatitis virusassociated intrahepatic cholangiocarcinoma has specific histomorphological and genetic features remains to be unknown. In this study, we found hepatitis virus-associated intrahepatic cholangiocarcinoma tended to be of the mass-forming subtype with cholangiolar differentiation. In addition, we found that N-cadherin is a marker for this subgroup of tumor. N-cadherin-positive tumors are strongly associated with hepatitis virus infection and tend to have certain clinicopathological and molecular features different from N-cadherin-negative tumors. These novel findings suggest that the mass-forming type of intrahepatic cholangiocarcinoma can be further subcategorized according to microscopic differentiation patterns and immunophenotypic markers, and that such subclassification has etiological and pathogenic significance.

\section{Materials and methods}

\section{Study Subjects}

From 2000 to 2010, 170 patients with intrahepatic cholangiocarcinoma who received detailed pathological assessment and regular follow-up at the National Taiwan University Hospital were selected for this study. Of the 170 tumors, 59 were not resectable and were diagnosed by biopsy only; the other 111 were resected and available for analysis. All specimens were meticulously examined by one pathologist (Y-MJ) to exclude combined hepatocellular and cholangiocarcinoma. The clinical and serological data were obtained from chart review. The serological data used for statistical analysis is the highest value before definite treatment. The study was conducted according to regulations of the hospital's ethics committee and the specimens were anonymous and analyzed in a blinded manner.

\section{Immunohistochemical Analysis}

Tissue sections ( $5 \mu \mathrm{m}$ ) were dewaxed and rehydrated. Antigen retrieval was carried out by incubating the slides in $0.01 \mathrm{M}$ citric acid buffer at $100^{\circ} \mathrm{C}$ for $10 \mathrm{~min}$. After blocking with $3 \% \mathrm{H}_{2} \mathrm{O}_{2}$ and $5 \%$ fetal bovine serum, the slides were allowed to react with primary antibodies at $4^{\circ} \mathrm{C}$ overnight. The slides were then incubated with polymer-HRP reagent (BioGenex, San Ramon, CA, USA). The peroxidase activity was visualized with diaminobenzidine tetrahydroxychloride solution (BioGenex). The sections were counterstained with hematoxylin. For negative controls, the primary antibody was replaced with $5 \%$ fetal bovine serum. The primary antibodies used were directed against the following antigens: N-cadherin (clone IAR06, 1:100) (Leica Microsystems, Wetzlar, Germany); CD56 (clone 123C3.D5, 1:100) (Thermo Fisher Scientific, Fremont, CA, USA); carcinoembryonic antigen (CEA) (clone II-7, 1:50) (DAKO Cytomation, Carpinteria, CA, USA); MUC1 (clone SPM493, 1:100) (Thermo Fisher Scientific, Fremont, CA, USA); MUC2 (clone M53, 1:100) (Thermo Fisher Scientific); and p53 (clone DO-1, 1:50) (DAKO Cytomation). For each marker, positive staining in more than $5 \%$ tumor cells was considered positive.

\section{Mutation Analysis}

Analyses of $K-R A S$ and BRAF mutations were carried out using DNA extracted from formalin-fixed paraffin-embedded tissues. Briefly, $10 \mu \mathrm{m}$ sections were cut from paraffin blocks. The tumor parts are dissected and collected. Tumors with cancer cell density less than $10 \%$ were excluded because they were below the detection threshold of direct sequencing. Genomic DNA was extracted using a QIAamp DNA FFPE Tissue Kit (Qiagen, Santa Clarita, CA, USA) according to the manufacturer's protocol. Exon 2 of $K-R A S$ and exon 15 of $B R A F$, which contain mutation hot spots, were amplified 
by polymerase chain reaction. The primers used were as follows: K-RAS-F, 5'-GAATGGTCCTGCACC AGTAA-3', K-RAS-R, GTGTGACATGTTCTAATAT AGTCA; BRAF-F, TGCTTGCTCTGATAGGAAAAT GA, and BRAF-R, CCACAAAATGGATCCAGACA AC. After purification, direct sequencing was performed using an automated ABI 3770 sequencer (Applied BioSystems, Foster City, CA, USA).

\section{Statistical Analysis}

The data were analyzed using SPSS version 14.0 for Windows (SPSS Inc., Chicago, IL, USA). Correlation between viral hepatitis, $\mathrm{N}$-cadherin expression, and clinicopathological parameters was evaluated by $\chi^{2}$ tests, Student's $t$-tests, and Logistic regression. Twotailed $P<0.05$ was considered statistically significant.

\section{Results}

Of the 170 patients enrolled in the study, serological data for HBsAg and anti-HCV were available for 140:
52 and 16 were positive for $\mathrm{HBsAg}$ and anti-HCV, respectively, including two who were positive for both. Immunohistochemical staining for HBsAg of the non-tumorous liver parenchyma of resected specimen for those patients having no serological data identified three more HBsAg carriers. Therefore, at least 69 enrolled patients (41\%) were positive for hepatitis B and/or C. As the prevalence of hepatitis $\mathrm{B}$ and $\mathrm{C}$ in the adult population of Taiwan is about $15-20 \%,{ }^{19,20}$ the high rate of infection in patients with intrahepatic cholangiocarcinoma indicates that viral hepatitis is a risk factor for intrahepatic cholangiocarcinoma with an odds ratio (OR) of 2-2.7. The clinicopathological features of viral hepatitis-associated intrahepatic cholangiocarcinoma are listed in Table 1. Compared with the seronegative patients, viral hepatitis-associated intrahepatic cholangiocarcinomas were more frequent in men (68 vs $42 \%, P=0.002$ ). The mean age of patients with viral hepatitis $(57.88 \pm 12.73$ years) was approximately 4 years less than that of those without $(62.14 \pm 11.62$ years). Patients with

Table 1 Clinical features of hepatitis virus-associated and -unassociated intrahepatic cholangiocarcinoma

\begin{tabular}{|c|c|c|c|c|}
\hline & Hepatitis+ $(\mathrm{n}=69)$ & Hepatitis $-(\mathrm{n}=73)$ & OR $(95 \% C I)$ & $\mathrm{P}$-value \\
\hline \multicolumn{5}{|l|}{ Sex } \\
\hline Male & 47 & 31 & 2.89 & 0.002 \\
\hline Female & 22 & 42 & $1.38<\mathrm{OR}<6.11$ & \\
\hline Age (years) & $57.88 \pm 12.73$ & $62.14 \pm 11.62$ & & 0.04 \\
\hline \multicolumn{5}{|c|}{$\alpha$-Fetoprotein $(\mathrm{ng} / \mathrm{ml})$} \\
\hline$>31$ & 15 & 6 & 3.07 & 0.025 \\
\hline$<31$ & 48 & 59 & $1.01<\mathrm{OR}<9.69$ & \\
\hline \multicolumn{5}{|l|}{ CA19-9 (U/ml) } \\
\hline$>50$ & 38 & 50 & 0.89 & 0.77 \\
\hline$<50$ & 17 & 20 & $0.39<\mathrm{OR}<2.08$ & \\
\hline \multicolumn{5}{|l|}{$C E A(n g / m l)$} \\
\hline$\geq 3$ & 34 & 40 & 1.13 & 0.75 \\
\hline$<3$ & 24 & 32 & $0.53<$ OR2.42 & \\
\hline Size $(\mathrm{cm})$ & $5.46 \pm 2.82$ & $6.72 \pm 3.12$ & & 0.025 \\
\hline \multicolumn{5}{|l|}{ Resectable } \\
\hline Yes & 56 & 42 & 3.18 & 0.002 \\
\hline No & 13 & 31 & $1.40<\mathrm{OR}<7.33$ & \\
\hline \multicolumn{5}{|l|}{ Туре } \\
\hline Mass forming & 65 & 60 & 3.52 & 0.027 \\
\hline Intra/periductal & 4 & 13 & $0.99<\mathrm{OR}<13.62$ & \\
\hline \multicolumn{5}{|c|}{ Intrahepatic lithiasis } \\
\hline Yes & 2 & 8 & 0.25 & 0.064 \\
\hline No & 61 & 60 & $0.03<\mathrm{OR}<1.33$ & \\
\hline \multicolumn{5}{|l|}{ Hyperbilirubinemia } \\
\hline Yes & 8 & 15 & 0.52 & 0.17 \\
\hline No & 55 & 54 & $0.18<\mathrm{OR}<1.45$ & \\
\hline \multicolumn{5}{|l|}{ Morphology } \\
\hline Cholangiolar & 28 & 15 & 2.71 & 0.008 \\
\hline Bile duct & 40 & 58 & $1.21<\mathrm{OR}<6.12$ & \\
\hline \multicolumn{5}{|l|}{$N$-cadherin } \\
\hline Positive & 39 & 16 & 5.06 & 0.0002 \\
\hline Negative & 13 & 27 & $1.93<\mathrm{OR}<13.55$ & \\
\hline
\end{tabular}

CI, confident interval; OR, odds ratio. 
viral hepatitis were more likely to have elevated serum $\alpha$-fetoprotein levels, but the serum levels of CA19-9 and CEA were not different from uninfected patients. Although not statistically significant, patients with viral hepatitis tended to be less likely to have intrahepatic lithiasis and presented with hyperbilirubinemia. Morphologically, viral hepatitis-associated intrahepatic cholangiocarcinomas were more likely to be of the mass-forming rather than the intraductal/periductal type $(\mathrm{OR}=3.52$, $P=0.027$ ). Viral hepatitis-associated intrahepatic cholangiocarcinomas were more amenable to surgical resection $(P=0.002)$.

Histopathological examination revealed that many viral hepatitis-associated intrahepatic cholangiocarcinomas were composed of cuboidal tumor cells having scanty eosinophilic cytoplasm and arranged in small monotonous glands (Figure 1a and b). Focally, such tumor cells were arranged in antlerlike, anastomosing patterns. At the junction of tumor and uninvolved liver parenchyma, the tumor cells tend to form small cords that directly connect with liver trabeculae. No mucin production was seen in these tumors. This histological feature is reminiscent of cholangioles (canals of Hering), and so we defined a tumor consisting of more than $80 \%$ of this pattern as a 'cholangiolar' subtype of intrahepatic cholangiocarcinoma. In contrast, intrahepatic cholangiocarcinomas not associated with viral hepatitis were more likely to be composed of columnar tumor cells having abundant pink cytoplasm and mucin production (Figure 1c and d), which we defined as a 'bile duct' subtype of intrahepatic cholangiocarcinoma. Statistical analysis reveals that the 'cholangiolar' subtype was more strongly associated viral hepatitis than the 'bile duct' subtype of ICC $(\mathrm{OR}=2.71$, $P=0.008$ ).

$\mathrm{N}$-cadherin is a recently identified marker of hepatobiliary tumors. ${ }^{21} \mathrm{~N}$-cadherin is expressed in a membranous pattern in hepatocytes, interlobular bile ducts, and ductular reactions, but not in extrahepatic and large intrahepatic bile ducts
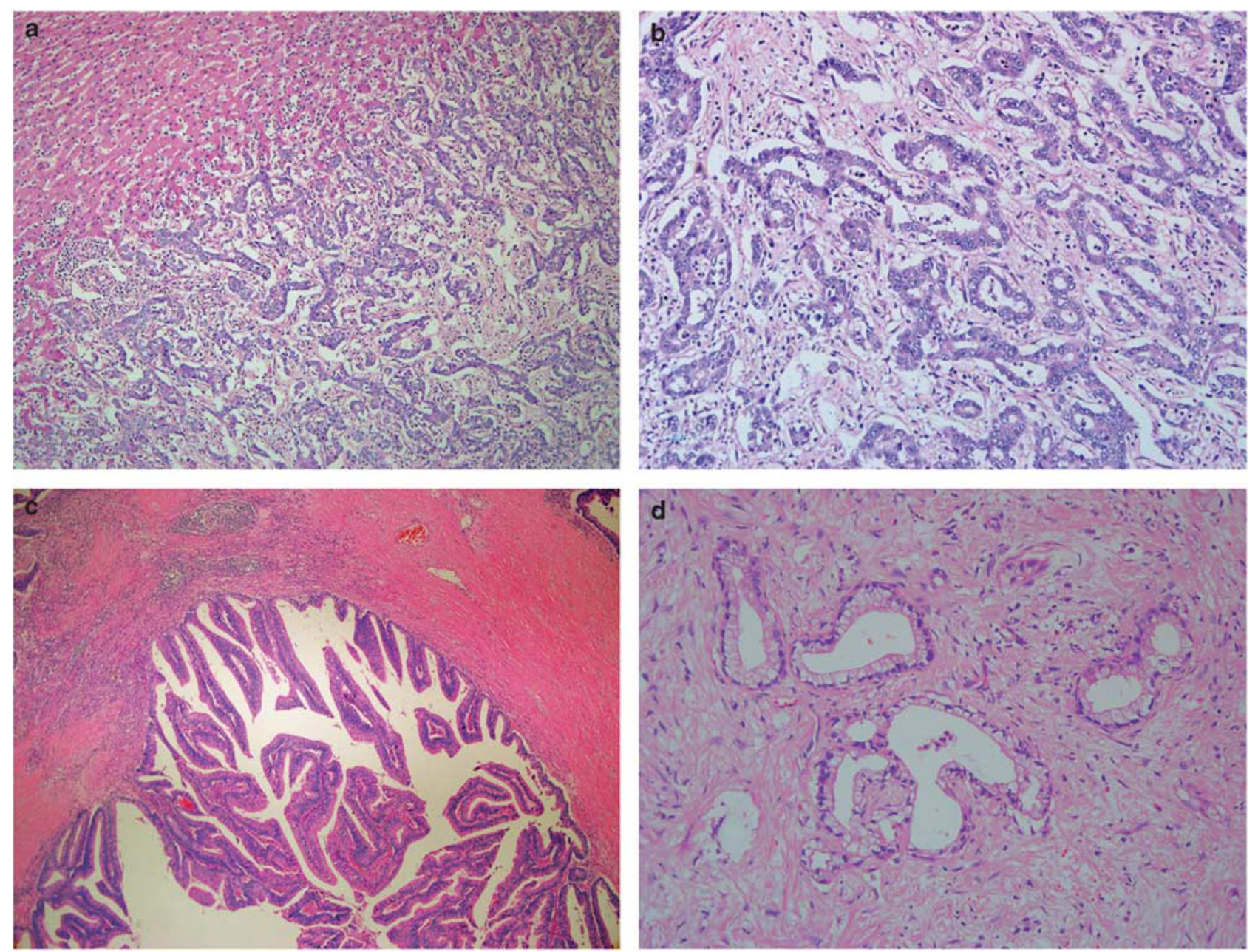

Figure 1 Morphology of intrahepatic cholangiocarcinoma. (a, b) A tumor of cholangiolar pattern in a hepatitis B carrier. The tumor cells are cuboidal, have scanty cytoplasm, and arranged in anastomosing glandular pattern. The tumor cells tend to form small cords that directly connect with liver trabeculae at the junction of tumor and uninvolved liver parenchyma (a). (c) Intraductal papillary proliferation of tumor cells in a patient with hepatolithasis. (d) 'Bile duct' pattern. The tumor cells are columnar and large with abundant mucinous cytoplasm (original magnification: (a) $\times 100,(\mathbf{b}) \times 200,(\mathbf{c}) \times 100$, and (d) $\times 200$ ). 

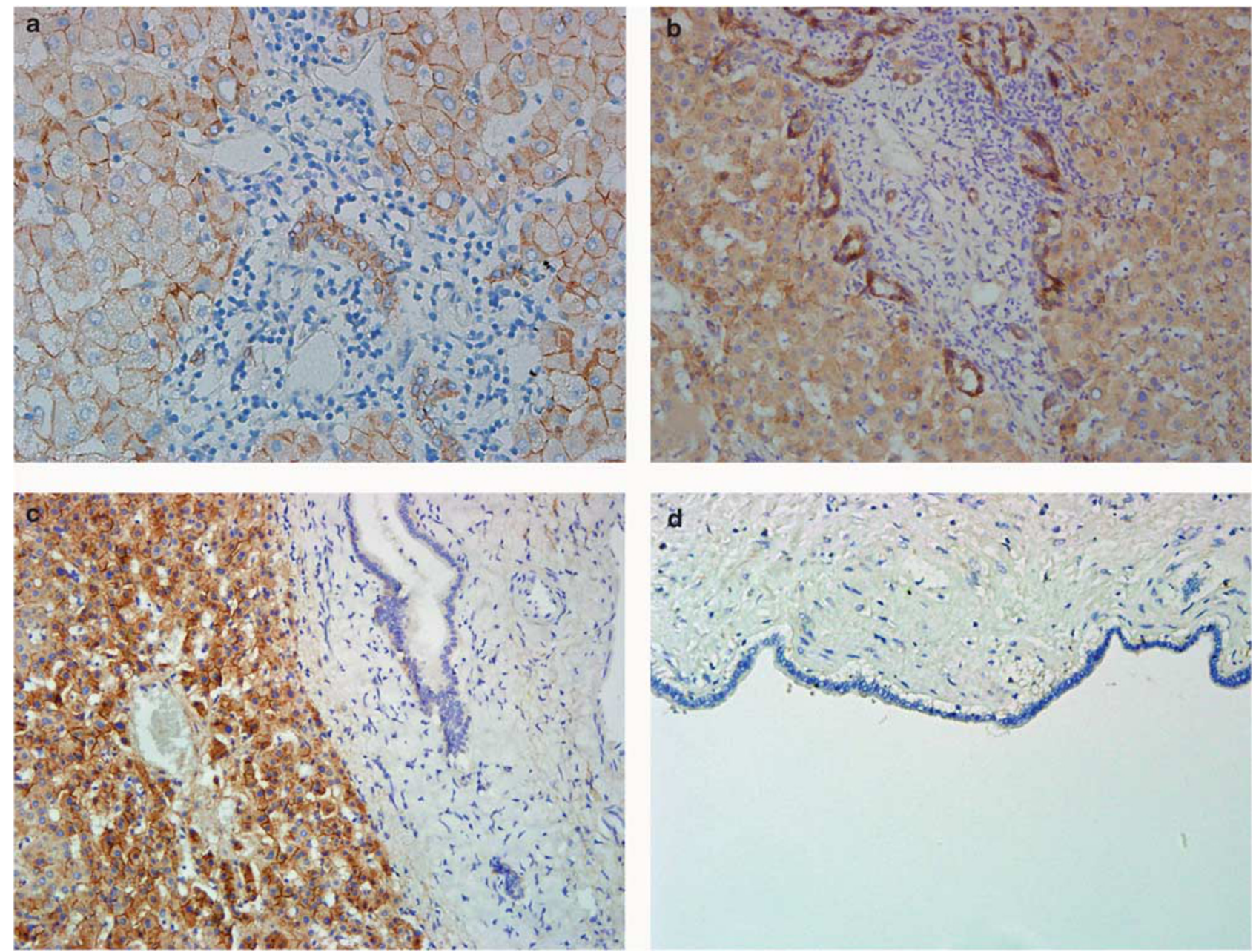

Figure $2 \mathrm{~N}$-cadherin expression in non-tumorous liver parenchyma and bile duct. N-cadherin is expressed in hepatocytes (a-c), interlobular bile ducts (a), and ductular reaction (b), but not in large intrahepatic bile duct (c) and extrahepatic bile duct (d) (original magnification: (a) $\times 400$, (b) $\times 200$, (c) $\times 100$, and (d) $\times 200)$.

(Figure 2). N-cadherin is more frequently expressed in peripheral than in hilar cholangiocarcinomas, ${ }^{21}$ which suggests that N-cadherin is more likely to be expressed in tumors differentiating toward small bile duct morphology. Therefore, we tested the expression of $\mathrm{N}$-cadherin in resected specimen of intrahepatic cholangiocarcinomas and found $\mathrm{N}$-cadherin expression was highly correlated with viral hepatitis infection $(\mathrm{OR}=5.06, P=0.0002)$ (Figure 3).

To identify independent factors associated with viral hepatitis, we put the clinicopathological factors analyzed in Table 1 in a multivariate analysis using Cox's proportional hazards model. N-cadherin expression is the only independent factor associated with viral hepatitis (adjusted $\mathrm{OR}=6.322, P=0.001$, 95\% CI: $11<$ OR < 18.97).

As N-cadherin immunopositivity is the only independent factor with virus status, we decided to reclassify intrahepatic cholangiocarcinomas according to N-cadherin status. N-cadherin was positive in 56 of 111 resected intrahepatic cholangiocarcinomas (51\%) (Table 2). All N-cadherin-positive tumors were of the mass-forming type. Clinically, N-cadherin expression was negatively associated with intrahepatic lithiasis $(P=0.003)$. Patients with $\mathrm{N}$-cadherin-positive tumors were more likely to have elevated serum $\alpha$-fetoprotein levels $(P=0.013)$, but levels of CA19-9 and CEA were not statistically different from those in N-cadherinnegative tumors. Importantly, N-cadherin expression was strongly associated with viral hepatitis $(P=0.0003)$ and the 'cholangiolar' morphology $(P=0.000003)$. The prevalence of viral hepatitis in patients having tumors expressing $\mathrm{N}$-cadherin was $75 \%$. In contrast, the prevalence rate of viral hepatitis in the negative group is only $37 \%$.

To further identify molecular character of $\mathrm{N}$-cadherin-positive intrahepatic cholangiocarcinoma, we performed immunostaining for CEA, CA19-9, MUC1, and MUC2 (Figure 3). CA19-9 was strongly positive in all cases tested and also positive in 
non-neoplastic bile ducts, so the staining was unrevealing. CEA was more frequently expressed in $\mathrm{N}$-cadherin-negative ICCs (OR $=0.12, P=0.0000005)$. Because N-cadherin-negative cholangiocarcinomas were more likely to have visible mucin in the lumen and cytoplasm of tumor cells, we were interested in whether there were differences in the expression of mucin apoproteins between the two types of cancers. Indeed, we found $\mathrm{N}$-cadherin-negative cholangiocarcinomas expressed MUC2 more frequently $(P=0.000001)$, but the expression of MUC1 was not different between the two groups of tumors.

$K-R A S$ and BRAF have been reported to be frequently mutated in cholangiocarcinomas, but not in HCC. ${ }^{22,23}$ Direct sequencing in 99 resected cholangiocarcinomas revealed that 13 tumors harbored mutations of codon 12 or 13 in K-RAS, but no mutation in $B R A F$ was detected. K-RAS mutations were more frequently detected in $\mathrm{N}$-cadherin-negative tumors $(\mathrm{OR}=0.24, P=0.039)$.

\section{Discussion}

Several etiological factors, including hepatolithiasis, infestation of liver flukes, primary sclerosing cholangitis, and Thorotrast exposure, are well known to be associated with increased risk of cholangiocarcinoma, but these factors are not identified in most cases of cholangiocarcinoma. Recently, several reports have suggested that infection with hepatitis B or $\mathrm{C}$ virus is a possible etiological factor for cholangiocarcinoma. ${ }^{8,9,16-18}$ Viral hepatitis-associated cholangiocarcinomas have some clinical features in common with hepatocellular carcinoma. They tend to occur at an earlier age, affect men more frequently, are more likely to cause elevated serum $\alpha$-fetoprotein levels, and less likely to cause elevated serum CA19-9 levels. However, until now there has been no histomorphological or genetic evidence that hepatitis-associated intrahepatic cholangiocarcinomas are different from those arising from patients without hepatotropic virus infection.
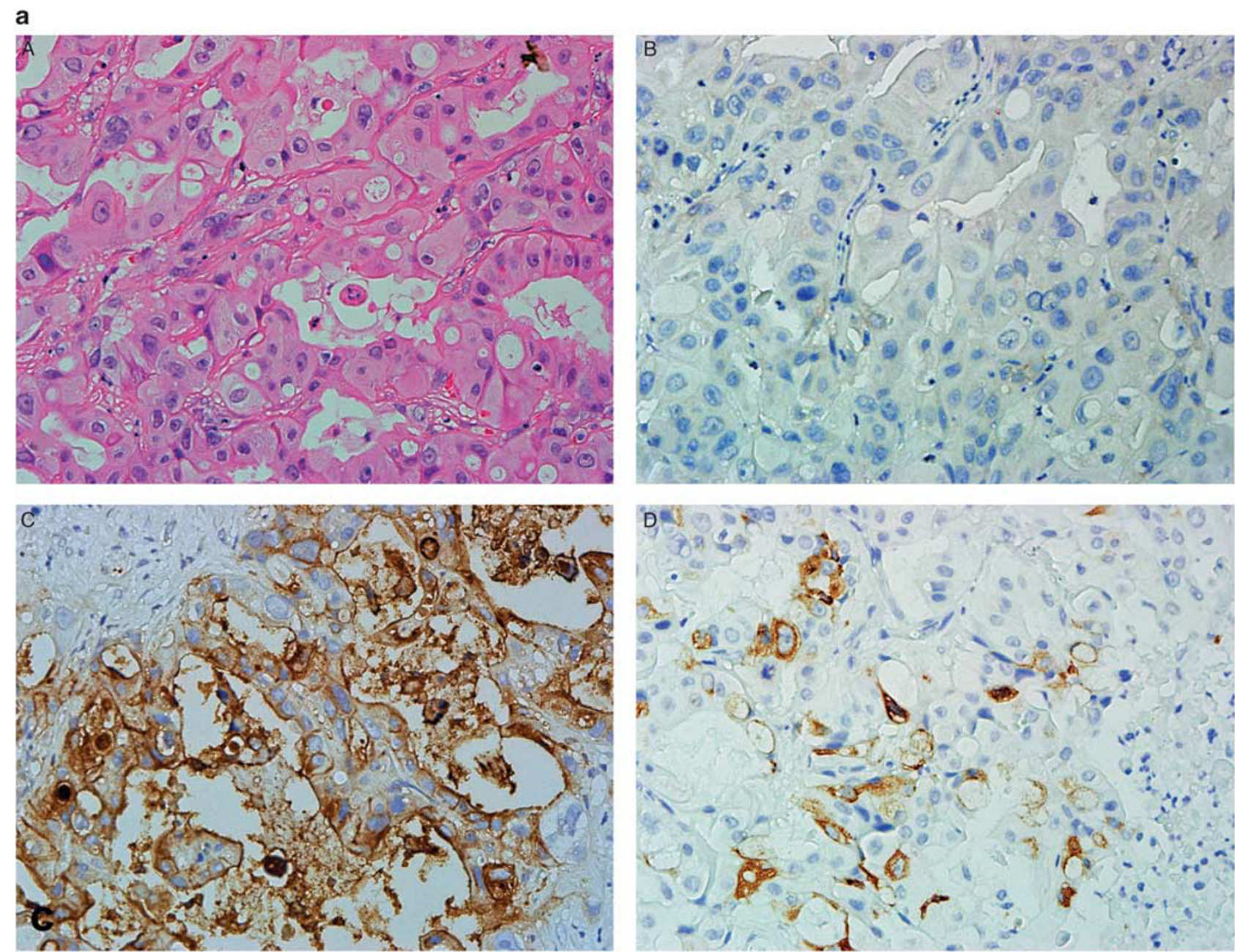

Figure 3 Typical morphology and immunophenotype of viral hepatitis-related and -unrelated intrahepatic cholangiocarcinomas. (a) A tumor from a patient without viral hepatitis. The tumor cells have 'bile duct' morphology (A), are negative for N-cadherin (B), and positive for CEA (C) and MUC2 (D). (b) A viral hepatitis-related intrahepatic cholangiocarcinoma. The tumor cells have 'cholangiolar morphology (B), are positive for N-cadherin, and negative for CEA (C) and MUC2 (D) (original magnification: $\times 400$ ). 
b
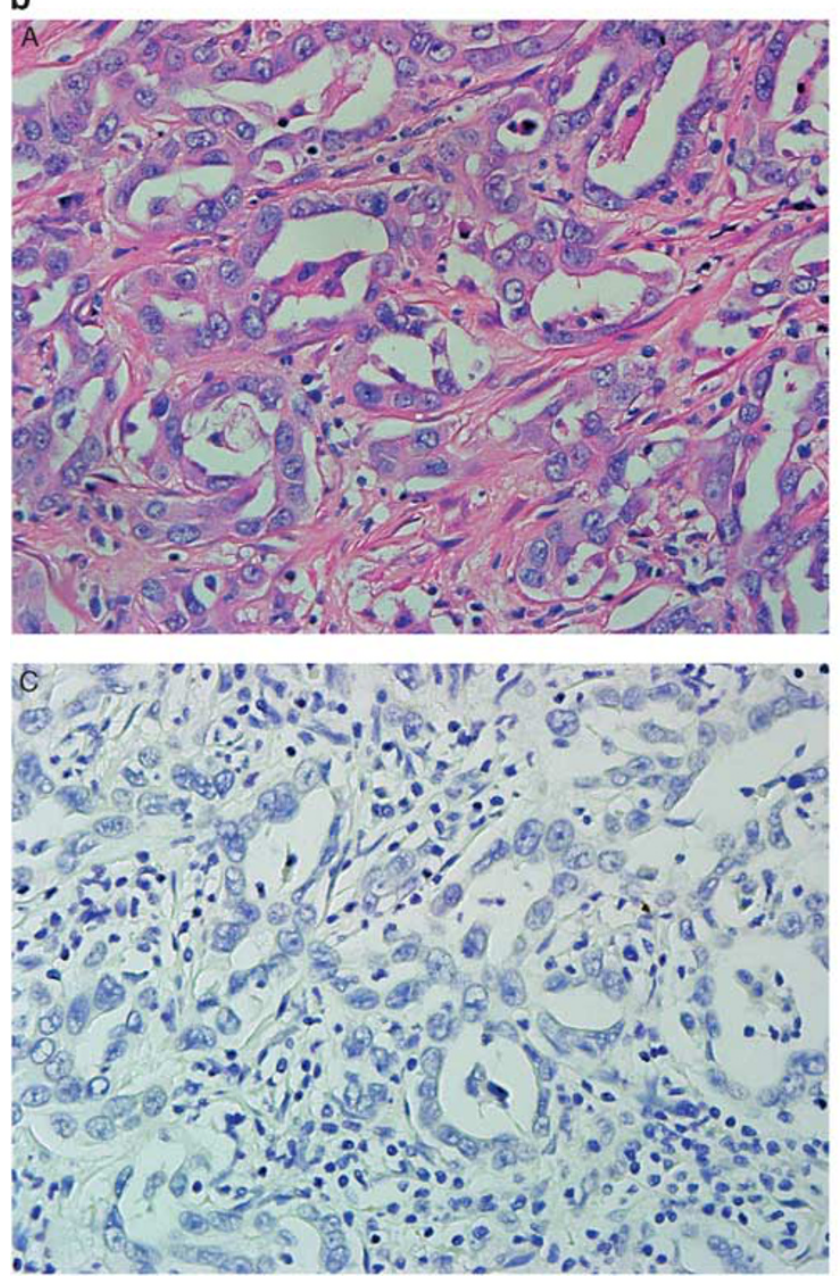
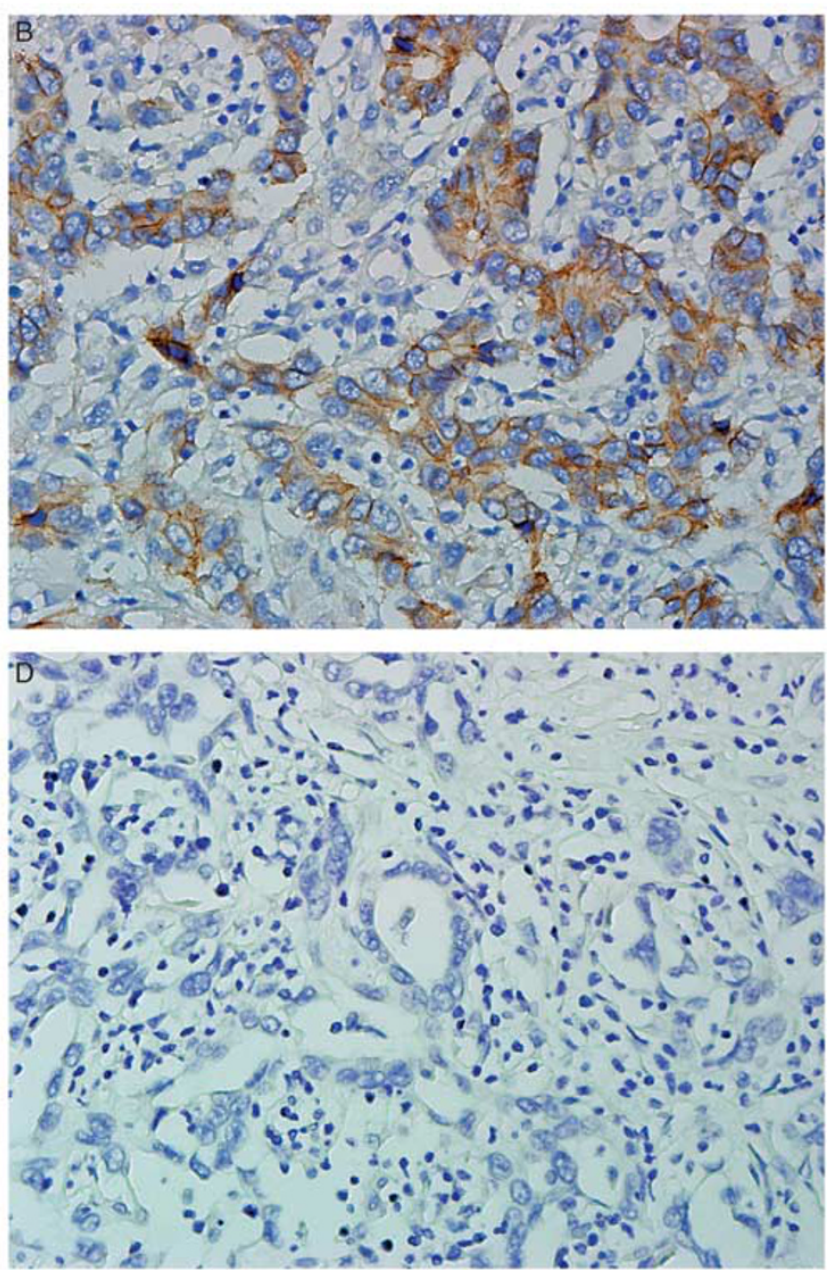

Figure 3 Continued.

In this report, we confirmed that viral hepatitis is a risk factor for intrahepatic cholangiocarcinoma in Taiwan. However, as the prevalence of viral hepatitis B and C is about $15-20 \%$ in the adult population of Taiwan, it is inevitable that many cases of intrahepatic cholangiocarcinoma developing in these patients actually are not etiologically related to the infection. In fact, by comparing the positive rates of viral hepatitis in patients with intrahepatic cholangiocarcinoma $(40.6 \%)$ and the general adult population (15-20\%), we can deduce that about $40-50 \%$ of viral hepatitis-associated intrahepatic cholangiocarcinoma is not etiologically related to the infection. Therefore, it is mandatory to identify the subgroup of intrahepatic cholangiocarcinoma that is strongly associated with viral hepatitis. Indeed, we found that viral hepatitis-associated ICC tends to share certain epidemiological and morphological features. These tumors are characterized by the mass-forming growth pattern, and cholangiolar glandular morphology.

The biliary tree is composed of ducts of different calibers. The large and small bile ducts are susceptible to different disease processes, indicating that various ductal cells have some intrinsic differences. The terminal branches of bile ducts-portal interlobular bile ducts and bile ductules-are where bipotential hepatic progenitor cells reside. ${ }^{24}$ Previous reports state that tumors with cholangiolar differentiation are likely to be originated from hepatic progenitor cells. ${ }^{25}$ Hepatotrophic viruses are capable of infecting mature hepatocytes and hepatic progenitor cells, but not bile duct cells. ${ }^{26}$ Therefore, it is reasonable to hypothesize that tumors with cholangiolar differentiation originated from hepatic progenitor cells. Injury of liver parenchyma caused by virus infection induces proliferation of these progenitor cells, which are capable of differentiating into hepatocytes and biliary epithelial cells. ${ }^{26}$ These progenitor cells are considered to be a target cell population for carcinogenesis. Most viral hepatitisassociated liver cancers show complete hepatocellular differentiation. Some hepatocellular carcinomas show incipient biliary differentiation, characterized by the expression of biliary cytokeratin CK19, fibrotic stroma, lymph node metastasis, and poor prognosis. ${ }^{27}$ Rarely, hepatocellular carcinoma and cholangiocarcinoma components can be 
Table 2 Clinicopathological significance of N-cadherin expression in resected intrahepatic cholangiocarcinoma

\begin{tabular}{|c|c|c|c|c|}
\hline & $\begin{array}{l}\text { N-cadherin+ } \\
\text { (total } \mathrm{n}=56 \text { ) }\end{array}$ & $\begin{array}{l}N \text {-cadherin- } \\
\text { (total } \mathrm{n}=55 \text { ) }\end{array}$ & $\begin{array}{l}\text { Odds ratio } \\
(95 \% \text { CI })\end{array}$ & $\mathrm{P}$-value \\
\hline \multicolumn{5}{|l|}{ Sex } \\
\hline Male & 33 & 25 & 1.72 & \multirow[t]{2}{*}{0.185} \\
\hline Female & 23 & 30 & $0.81<\mathrm{OR}<3.65$ & \\
\hline Age (years) & $57.86 \pm 12.33$ & $63.69 \pm 10.11$ & & 0.008 \\
\hline \multicolumn{5}{|c|}{$\alpha$-Fetoprotein $(\mathrm{ng} / \mathrm{ml})$} \\
\hline$\geq 31$ & 13 & 3 & 5.02 & \multirow[t]{2}{*}{0.013} \\
\hline$<31$ & 38 & 44 & $1.33<\mathrm{OR}<18.94$ & \\
\hline \multicolumn{5}{|l|}{ CA19-9 (U/ml) } \\
\hline$\geq 50$ & 26 & 38 & 0.49 & \multirow[t]{2}{*}{0.128} \\
\hline$<50$ & 18 & 13 & $0.21<\mathrm{OR}<1.18$ & \\
\hline \multicolumn{5}{|l|}{$C E A(n g / m l)$} \\
\hline$\geq 3$ & 27 & 35 & 0.51 & \multirow[t]{2}{*}{0.155} \\
\hline$<3$ & 24 & 16 & $0.23<\mathrm{OR}<1.15$ & \\
\hline Size $(\mathrm{cm})$ & $4.98 \pm 2.65$ & $5.98 \pm 2.51$ & & 0.062 \\
\hline \multicolumn{5}{|l|}{ Tyре } \\
\hline Mass forming & 56 & 41 & & \multirow[t]{2}{*}{0.00002} \\
\hline Intra/periductal & 0 & 14 & & \\
\hline \multicolumn{5}{|l|}{ Viral hepatitis } \\
\hline Yes & 39 & 16 & 5.06 & \multirow{2}{*}{0.0003} \\
\hline No & 13 & 27 & $2.10<\mathrm{OR}<12.22$ & \\
\hline \multicolumn{5}{|c|}{ Intrahepatic lithiasis } \\
\hline Yes & 0 & 9 & & \multirow[t]{2}{*}{0.003} \\
\hline No & 52 & 43 & & \\
\hline \multicolumn{5}{|l|}{ Hyperbilirubinemia } \\
\hline Yes & 3 & 7 & 0.39 & \multirow{2}{*}{0.319} \\
\hline No & 49 & 45 & $0.10<\mathrm{OR}<1.61$ & \\
\hline \multicolumn{5}{|l|}{ Morphology } \\
\hline Cholangiolar & 31 & 7 & 8.50 & \multirow[t]{2}{*}{0.000003} \\
\hline Bile duct & 25 & 48 & $3.28<\mathrm{OR}<22.03$ & \\
\hline \multicolumn{5}{|c|}{ CEA immunostaining } \\
\hline Positive & 13 & 39 & 0.12 & \multirow[t]{2}{*}{0.0000005} \\
\hline Negative & 43 & 16 & $0.05<\mathrm{OR}<0.29$ & \\
\hline \multicolumn{5}{|c|}{ MUC1 immunostaining } \\
\hline Positive & 48 & 39 & 2.31 & \multirow[t]{2}{*}{0.103} \\
\hline Negative & 8 & 15 & $0.89<\mathrm{OR}<6.01$ & \\
\hline \multicolumn{5}{|c|}{ MUC2 immunostaining } \\
\hline Positive & 1 & 20 & 0.03 & \multirow[t]{2}{*}{0.000001} \\
\hline Negative & 55 & 34 & $0.00<\mathrm{OR}<0.24$ & \\
\hline \multicolumn{5}{|c|}{ K-RAS/BRAF mutation } \\
\hline Positive & 3 & 10 & 0.24 & \multirow[t]{2}{*}{0.039} \\
\hline Negative & 48 & 39 & $0.06<\mathrm{OR}<0.95$ & \\
\hline
\end{tabular}

CI, confident interval; OR, odds ratio.

identified in the same tumor. These combined tumors are usually hepatitis related. The mixed morphology strongly suggests that they originated from hepatic progenitor cells. ${ }^{14}$ Now, we add viral hepatitis-related intrahepatic cholangiocarcinomas to this spectrum.

The dichotomical division of intrahepatic cholangiocarcinoma into cholangiolar and bile duct subtypes is somewhat arbitrary; some tumors have morphological features intermediate between the two. Some tumors comprise different morphological patterns in different regions. Intra- and interobserver agreement difficulties regarding these diverse histological pictures will compromise application of this classification system. Therefore, an objective marker to differentiate these two groups of intrahepatic cholangiocarcinoma is needed. Initially, we tested bile ductule marker CD56, which was reported to be positive in reactive bile ductules in non-neoplastic liver disease. ${ }^{28}$ However, our initial 
screen showed that CD56 is rarely expressed in intrahepatic cholangiocarcinoma (data not shown), supporting the previous report by Gütgemann et al. ${ }^{29}$

$\mathrm{N}$-cadherin is expressed in hepatocytes, bile ductules, and small interlobular bile ducts, but not in large intrahepatic or extrahepatic bile ducts. The expression of $\mathrm{N}$-cadherin in intrahepatic cholangiocarcinoma suggests that this group is likely to originate in a carcinogenic process in portal progenitor cells or small interlobular bile ducts. Indeed, in this study, all cases of N-cadherin-positive intrahepatic cholangiocarcinoma were of the massforming type without the involvement of large bile ducts. In contrast, N-cadherin-negative intrahepatic cholangiocarcinomas included all our cases with periductal/intraductal growth patterns and some mass-forming ICCs. These observations suggest that $\mathrm{N}$-cadherin-positive and -negative intrahepatic cholangiocarcinomas may have different pathogenesis. The N-cadherin-positive group is more similar to hepatocellular carcinoma in terms of association with viral hepatitis, elevation of serum $\alpha$-fetoprotein level, lower age of onset, and infrequent $K-R A S$ mutation. The N-cadherin-negative intrahepatic cholangiocarcinomas are more similar to hilar and extrahepatic bile duct adenocarcinomas and are associated with other well-established etiological factors such as hepatolithiasis.

The morphology of the 'cholangiolar' pattern is similar to cholangiolocellular carcinoma reported by other groups. ${ }^{25}$ Cholangiolocellular carcinoma is defined as a tumor characterized by small cords resembling cholangioles and reactive-ductular reaction-like anastomosing glands in abundant fibrous stroma ${ }^{30}$ In a large series from Belgium, nine of 24 cases were viral hepatitis-related. Immunophenotypic analysis suggested a hepatic progenitor cell origin. ${ }^{25}$ However, cholangiolocellular carcinoma is considered to be a very rare tumor. Less than 50 cases have been reported. On examining the histological pictures in the literature, they are typically composed of low-grade tumor cells arranged in small glands or cords. Our definition of the 'cholangiolar pattern' encompasses all histological grades and has more variable histological patterns as long as the tumor cells are cuboidal with scanty cytoplasm. Therefore, we do not adopt the term 'cholangiolocellular carcinoma' to describe this group of tumors. Our definition of 'cholangiolar' is justified by the strong association with viral hepatitis.

This subclassification of intrahepatic cholangiocarcinomas based on a single marker is still far from satisfactory. We can occasionally identify rare $\mathrm{N}$-cadherin-positive intrahepatic cholangiocarcinomas with bile duct-type morphology and unassociated with viral hepatitis. In addition, the prevalence of viral hepatitis in the $\mathrm{N}$-cadherin-negative group is about $35 \%$, still higher than the prevalence of viral hepatitis in the adult population of Taiwan. These results indicate that some intrahepatic cholangiocarcinomas are misclassified or that viral hepatitis still confers a lower risk for N-cadherinnegative intrahepatic cholangiocarcinomas. Further studies using genome-wide tools, such as cDNA microarray methods, may provide a more accurate system of classification.

The clinical significance of this novel approach to classification of intrahepatic cholangiocarcinoma is still unclear. N-cadherin expression did not appear to be correlated with prognosis in our patients (data not shown). Hepatocellular carcinomas are amenable to several locoregional and systemic treatment modalities, which are largely ineffective for intrahepatic cholangiocarcinomas. Combined hepatocellular and cholangiocarcinoma can be effectively treated by transarterial chemoembolization. ${ }^{31}$ Because of similar pathogenesis and molecular alterations, studies designed to ascertain whether $\mathrm{N}$-cadherin-positive viral hepatitis-related intrahepatic cholangiocarcinoma can be successfully treated with the methods used to treat hepatocellular carcinoma should be conducted.

\section{Acknowledgement}

This work is financial supported by Grant NTUH 100-S1503, National Taiwan University Hospital, to Y-MJ and 96-2628-B-002-054-MY3, National Science Council, to H-C Hsu.

\section{Disclosure/conflict of interest}

The authors declare no conflict of interest.

\section{References}

1 Okuda K, Nakanuma Y, Miyazaki M. Cholangiocarcinoma: recent progress. Part 1: epidemiology and etiology. J Gastroenterol Hepatol 2002;17:1049-1055.

2 Kurathong S, Lerdverasirikul P, Wongpaitoon V, et al. Opisthorchis viverrini infection and cholangiocarcinoma: a prospective, case-controlled study. Gastroenterology 1985;89:151-156.

$3 \mathrm{Lim} \mathrm{MK}, \mathrm{Ju} \mathrm{YH}$, Franceschi S, et al. Clonorchis sinensis infection and increasing risk of cholangiocarcinoma in the Republic of Korea. Am J Trop Med Hyg 2006;75:93-96.

4 Ohta G, Nakanuma Y, Terada T. Pathology of hepatolithiasis: cholangitis and cholangiocarcinoma. Prog Clin Biol Res 1984;152:91-113.

5 Tamir BM. Risk factors for cholangiocarcinoma. Eur J Gastroenterol Hepatol 2007;19:615-617.

6 Lazaridis KN, Gores GJ. Primary sclerosing cholangitis and cholangiocarcinoma. Semin Liver Dis 2006;26:42-51.

7 Lipshutz GS, Brennan TV, Warren RS. Thorotrastinduced liver neoplasia: a collective review. J Am Coll Surg 2002;195:713-718.

8 Kobayashi M, Ikeda K, Saitoh S, et al. Incidence of primary cholangiocellular carcinoma of the liver in Japanese patients with hepatitis C virus-related cirrhosis. Cancer 2000;88:2471-2477. 
9 Lee TY, Lee SS, Jung SW, et al. Hepatitis B virus infection and intrahepatic cholangiocarcinoma in Korea: a case-control study. Am J Gastroenterol 2008;103:1716-1720.

10 Andersona CD, Pinsona CW, Berlinb J, et al. Diagnosis and treatment of cholangiocarcinoma. Oncologist 2004;9:43-57.

11 Yamasaki S. Intrahepatic cholangiocarcinoma: macroscopic type and stage classification. J Hepatobiliary Pancreat Surg 2003;10:288-291.

12 Jang KT, Hong SM, Lee KT, et al. Intraductal papillary neoplasm of the bile duct associated with Clonorchis sinensis infection. Virchows Arch 2008;453:589-598.

13 Chen TC, Nakanuma Y, Zen Y, et al. Intraductal papillary neoplasia of the liver associated with hepatolithiasis. Hepatology 2001;34:651-658.

$14 \mathrm{Koh}$ KC, Lee H, Choi MS, et al. Clinicopathologic features and prognosis of combined hepatocellular cholangiocarcinoma. Am J Surg 2005;189:120-125.

15 Zhang F, Chen XP, Zhang W, et al. Combined hepatocellular cholangiocarcinoma originating from hepatic progenitor cells: immunohistochemical and double-fluorescence immunostaining evidence. Histopathology 2008;52:224-232.

16 Hai S, Kubo S, Yamamoto S, et al. Clinicopathologic characteristics of hepatitis $C$ virus-associated intrahepatic cholangiocarcinoma. Dig Surg 2005;22:432-439.

17 Lee CH, Chang CJ, Lin YJ, et al. Viral hepatitisassociated intrahepatic cholangiocarcinoma shares common disease processes with hepatocellular carcinoma. Br J Cancer 2009;100:1765-1770.

18 Zhou H, Wang H, Zhou D, et al. Hepatitis B virusassociated intrahepatic cholangiocarcinoma and hepatocellular carcinoma may hold common disease process for carcinogenesis. Eur J Cancer 2010;46: 1056-1061.

19 Chen DS. Viral hepatitis in East Asia. J Formos Med Assoc 1996;95:6-12.

20 Chen CH, Yang PM, Huang GT, et al. Estimation of seroprevalence of hepatitis $B$ virus and hepatitis $C$ virus in Taiwan from a large-scale survey of free hepatitis screening participants. J Formos Med Assoc 2007;106:148-155.

21 Mosnier J-F, Kandel C, Cazals-Hatem D, et al. $\mathrm{N}$-cadherin serves as diagnostic biomarker in intrahepatic and perihilar cholangiocarcinomas. Mod Pathol 2009;22:182-190.

22 Tannapfel A, Sommerer F, Benicke M, et al. Mutations of the BRAF gene in cholangiocarcinoma but not in hepatocellular carcinoma. Gut 2003;52:706-712.

23 Tada M, Omata M, Ohto M. Analysis of ras gene mutations in human hepatic malignant tumors by polymerase chain reaction and direct sequencing. Cancer Res 1990;50:1121-1124.

24 Zhang Y, Bai XF, Huang CX. Hepatic stem cells: existence and origin. World J Gastroenterol 2003;9: 201-204.

25 Komuta M, Spee B, Borght SV, et al. Clinicopathological study on cholangiolocellular carcinoma suggesting hepatic progenitor cell origin. Hepatology 2008;47:1544-1556.

26 Roskams T. Liver stem cells and their implication in hepatocellular and cholangiocarcinoma. Oncogene 2006;25:3818-3822.

27 Uenishi T, Kubo S, Yamamoto T, et al. Cytokeratin 19 expression in hepatocellular carcinoma predicts early postoperative recurrence. Jpn J Cancer Res 2003;94: 851-857.

28 Torbenson M, Wang J, Abraham S, et al. Bile ducts and ductules are positive for CD56 (N-CAM) in most cases of extrahepatic biliary atresia. Am J Surg Pathol 2003;27:1454-1457.

29 Gütgemann I, Haas S, Berg JP, et al. CD56 expression aids in the differential diagnosis of cholangiocarcinomas and benign cholangiocellular lesions. Virchows Arch 2006;448:407-411.

30 Steiner PE, Higginson J. Cholangiolocellular carcinoma of the liver. Cancer 1959;12:753-759.

$31 \mathrm{Kim} \mathrm{JH}$, Yoon HK, Ko GY, et al. Nonresectable combined hepatocellular carcinoma and cholangiocarcinoma: analysis of the response and prognostic factors after transcatheter arterial chemoembolization. Radiology 2010;255:270-277. 